\title{
Safety Hazards Identification of Construction Site Layout Based on Geographic Information System (GIS)
}

\author{
Diah Sarasanty ${ }^{\mathrm{a}}$ \\ ${ }^{a}$ Department of Civil Engineering, Faculty of Engineering, Universitas Islam Majapahit, Mojokerto, East Java, Indonesia \\ E-mail: diahsarasanty@gmail.com
}

\begin{abstract}
In the world's gross domestic product, the construction industry accounts for about $10 \%$ and plays a significant role in the eastern and western economies. Hectic places, unique characteristics, and an ever-changing work environment and its dynamic nature make construction sites challenging to predict before construction or during the life cycle project. The physical and psychological problems of construction workers caused by the construction site's poor safety, economically, significantly affect the project with a significant increase in costs. This study aims to identify occupational safety hazards by proposing occupational safety hazards in predicting worker safety hazards at construction sites. In this research, GIS is used to present the relationship between temporary facilities and safety issues at construction sites to improve the accuracy of identifying work accidents. The data collection stages were carried out through a location survey, geographic spatial, and interviews by SHE managers on a high-rise building construction project. The site layout's dynamic safety assessment is a step in GIS development in obtaining the safety zone accuracy around the temporary construction facility. It was found that there is a combination of GIS capabilities in the accuracy of site layout, which can significantly increase safety at the construction site to obtain recommendations for safety measures and minimize the occurrence of work accident fatalities through preventive actions.
\end{abstract}

Keywords - safety hazards; site layout construction; geographic information system.

\section{INTRODUCTION}

Construction remains to be the most dangerous industry in terms of the total number of deaths [1]. In 2005, the construction industry experienced 1243 total deaths or $21 \%$ of all work-related fatalities in the United States [2]. In 2015 there were approximately 4,836 workers who died due to injuries from work. The projected number is the highest since 2008 and has increased from 2014. The number of work accidents has increased from year to year, with a trend of 5\% [3]. Planning in construction projects becomes very difficult due to uncertainty and high complexity [4]. The increased likelihood of accidents due to the disorderly placement of construction resources emphasizes site layout planning [5]. Construction methods, scale and type of project, project site conditions, and operational safety management standards are a set of several factors that influence the safety of a construction project [6]. The availability of a working environment at a safe construction site and applying a safety management system to minimize injuries have been carried out by several construction companies throughout the world [7]. However, in 2013 it increased the rate of fatality to 2.9 times compared to other industries. This rate can be seen from the decrease in construction safety improvement [8].

Economic, safety, and other aspects are significantly affected by the importance of the construction site layout. The emergence of unexpected costs is one result of the hazards of safety at the construction site. In addition to the resources of money, duration of time, allocation of material, construction workers, and the equipment, the construction site space is as important as these resources [9]. The lack of labor efficiency, repositioning temporary facilities is a result of spend due time by improper site layout planning [10]. These reasons make it necessary to synergize all existing facilities, topography, environment so that construction planning is one unit and not separate [11]. The increased safety of the construction site's site layout will precisely affect the construction of site layout, contributing significantly to construction safety, cost reduction, and material travel distance [12], [33]. Consideration of the application of the construction layout and to organize the construction of sites has not been based on previous studies. The importance of developing appropriate guidelines in the first stages of the construction life cycle project can avoid hazards from death [13].

The application of procedures and equipment arrangements in the workplace is determined before the 
operational phase-in safety. Trending topics that analyze the predefined of facilities in the space available on the site are relatively high. Consideration in choosing practical application models is one of the things that can improve safety on construction sites [14]. Optimization of site space in meeting the needs of storage space, fabrication, and material assembly at the location has been examined by several previous studies [15]-[18]. Application and development of models in solving site layout of construction problems based on knowledge systems as well as CAD (Computer-Aided Design), CONSITE, SightPlan, MovePlan, MoveSchedule, fuzzy, and Building Information Modelling have been made in providing solutions to site layout problems [19],[20]. The use of BIM and 4-dimensional CAD has limitations in factor analysis of environmental conditions, route access, topographic location, thermal comfort, and analysis which includes the planning of safety measures as evaluation material for new locations affected by floods, vehicle access routes carrying material shipments, drainage planning, and others [11], [21], [22], [34]. The spatial feasibility of construction planning significantly influences smoothness in the implementation of the method.

GIS assists planners in modeling spatial relationships and geometric and topological constraints that challenge the various building elements on the site [23],[24],[25]. Analysis, storage, display, geographic data input in computer systems is referred to as Geographic Information Systems (GIS) [26]. Intense spatial analysis data such as track width, lattice dimensions, storage area, and non-spatial including material properties and material storage life cycles which are a matter of material layout at construction sites can be accommodated by GIS. The advantages of integration of spatial and nonspatial properties in GIS help in site layout planning for example temporary facility automation in construction project layout [27], integration of material layout planning in the development of based cost estimation systems [28], optimizing the performance improvement of tunnel utilities in management maintenance [19],[29] .

The GIS discussion on temporal integration and sitespecific spatial information can formulate a 4D model of construction safety planning as a material for studying the layout of dynamic construction materials [30],[31],[32]. Emphasis on topographic information on the use of GIS is an excess that can reduce the occurrence of work accidents [11],[35],[36]. Optimization of material layout in planning has been done in previous studies and makes GIS's advantages in the spatiotemporal analysis. By combining data and safety knowledge, temporal information, spatial construction sites are carried out by the authors in this study. This paper aims to identify the safety hazards site layout of construction and propose a 3D model of construction safety planning approach based on spatial information integration to analyze risky work zones using Geographic Information System (GIS). Modelling construction sites and integrating safety databases in 3D space can provide evaluation actions when, where, and why safety measures need to be applied. The study results are expected to provide recommendations for preventive actions in the future and not to repeat the same conditions during the under-construction project.

\section{MATERIAL AND METHOD}

The method of safety hazards identification of construction site layout using the Geographic Information System it is presented in several stages, namely: (1) quantify activity risk that affects the work accident of construction project (2) obtaining risky work periods through safety schedule (3) estimate activity safety score from historical construction documents and confirmatory by site surveys, questionnaires and interviews with construction experts (HSE Manager) and (4) generated 3D simulation to prediction risky work zones. In identifying problems, effective safety techniques are combined from the views of experienced experts. Construction data obtained by interviews with professionals. Secondary data in the form of a safety documentation file that includes the active procedure and the regulatory reference code. The approach proposed in this study is to compile a list of activities and personnel involved, calculate safety scores that are affected by other activities so that the expected outputs can help all stakeholders in making effective decisions on work safety. Fig. 2 shows the safety score in the work zone by summarizing the estimated activity [22].

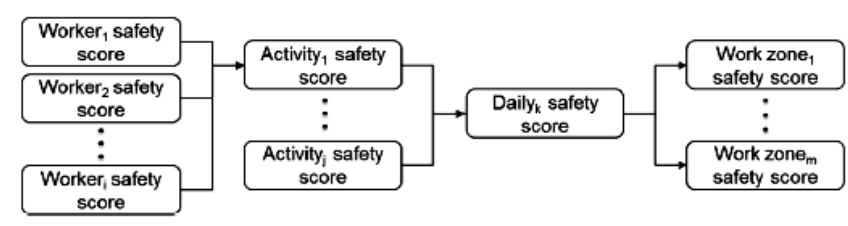

Fig. 1 Safety score estimation process (Choe [22]

The analysis of the factors that impress the risk of activities, including construction methods, work calendar periods, and others are done to determine the level of danger. Activity activities are collected through a safety documentation database, including codes and regulatory references that have relevance to the activities carried out. Regular updates and extensions to the safety documentation file as a source of additional information. Spatial and nonspatial secondary data collected related geographic locations and site topographical conditions. The safety score is an accumulation of the same activity quantified to estimate risk, type of accident, and injury source. The riskiest activities and safety measures that need to be implemented when hazards are identified can be prioritized from the quantification results. Integrated temporal information becomes very crucial when the complexity of the activities is high enough. The relationship between busy activities and increased schedule pressure is very important in measuring the time periods for high-risk work and resource availability. The integration provides space in estimating 3D models to represent work zones virtually. Temporal and spatial visualizations of safety scores provide an approximation of the hazards caused by other work activities. Dynamic control of the schedule can be applied so that periodic and proactive training can be prepared in advance at the project site. Spatial information integrated into real-time can visualize potential additional information that can then be developed into activities for all types of projects. This will be very useful in estimating the safety impact caused by other people's activities. 


\section{RESULTS AND DISCUSSION}

\section{A. Case Study}

The application of the Geographic Information System model is carried out by doing a model in terms of a high-rise building project in the city of Surabaya, Indonesia. The proposed safety analysis approach and barriers by applying it to an under-construction project. Project A is an apartment building project. Technical data gross square area of approximately $58,582.36 \mathrm{~m} 2$. This project consists of 38 floors for occupancy, 4 podium floors, and 3 floors of the basement area. The construct's scope is preparation work, structure, finishing, mechanical electrical, and plumbing (MEP). The construction project under review is an apartment building that has 35 tasks planned in the area under construction at the time this research was conducted. The analyzed building area includes basement floors 1 to 3 and the residential floors 1 to 3 , in the work breakdown structure of the construction work of the construction project in this case study. This research is divided into 4 major parts which are grouped at level 1. In the first group are several activities closely related to preparation works, including the construction of gates, access roads to the project, and drainage works. The second group part is an activity related to structure work such as capping beam, inclinometer, excavation, bore pile kingpost, steel beam, mass concrete, slab, basement wall, column, shear wall, beam, slab, and staircase. For finishing work related to floor work, interior and exterior walls, doors and windows, ceilings, sanitation, and facades are part of the third group's construction activities. Electrical, mechanical, and plumbing jobs are part of the fourth job, including mechanical ventilation, fire alarms, sound systems, elevators, and lifts. With the location survey-based collection technique, the work on the project under review is simulated in several work zones by planning GIS zoning in a 2D formula.

To facilitate GIS planning, the researcher describes the building in 3D view by generating it using Revit. In the realtime of the demonstration stage, construction is considered to use a GIS-based model with its ability to describe safety assessments on the layout of the construction site in the analyzed building illustrated in Fig. 2 .

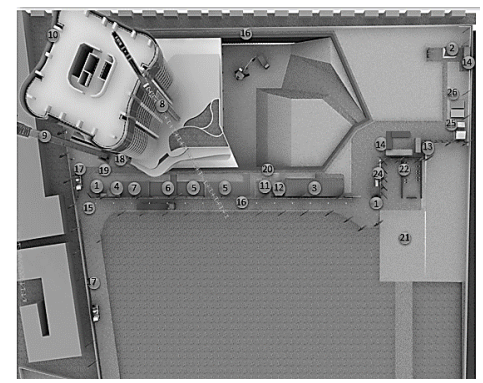

Fig. 2 General site layout of the case study

It can be seen in the site plan in general regarding the layout of high-rise buildings that are in the construction stage and generated 3D model illustrated by Fig. 3. The site facilities in the construction area divided by the primary facility are main gate dan site parking. Temporary facilities include material procurement area, steel yard, field office, washing bay, canteen, wood inventory, warehouse, generator room, and crane.

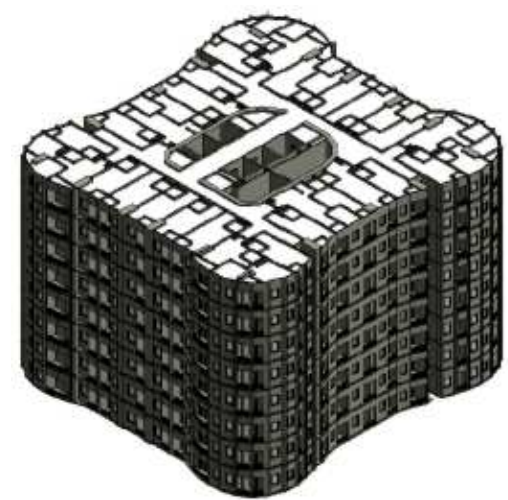

Fig. 3 3D model of the case study

\section{B. Discussion}

This study presents an evaluation model of the layout of a high-rise building construction project using a GIS. In the evaluation phase, identification and analysis of each activity's safety risks are carried out in Table 1. 4 top jobs are ranked as the most dangerous work risks, and top-down kingpost construction is the riskiest activity with a risk rating of 20. For the next most hazardous work, concrete shear walls identified about 25 risks as the most critical source of injury. Based on the analysis, results show, in general, the types of hazards in the activities carried out and identified as excavation, beam, and slab concrete. After activity safety risk analysis takes by project hazard identification and risk management documentation, safety scores in the ongoing activity are estimated. The output in the form of a safety site is the result of the integration of the activity schedule and the safety activity score. From the safety score, the classification is based on the work zone. The integration of $3 \mathrm{D}$ models visually illustrates the risk level when work zones have activities through floor-to-floor simulations.

Trending on safety score fluctuations results from a risk score profile, which has not explained the reasons for time and conditions that are more dangerous than other activities. Analysis related to the type of danger and source of injury is needed as additional information. Case study activities are planned in the same work zone. The determination is complemented by the number of activities, the level safety, management control, the level severity, and the likelihood occurring accident. The zoning plan is based on an analysis of risk by work zones and allocation of safety scores to zones with planned activities. 3D safety simulation is the result of work zone safety analysis in the form of a work zone safety with score visualization. As seen in Fig. 4, it describes the safety simulation in $2 \mathrm{D}$ and analysis of the work zone, specifically in basements 1 to 3 . In the simulation, the work zone is categorized as a work zone with visualization in three colors, including orange, with a low hazard risk level. The medium category is depicted in blue coloration, and the most at risk are classified in red color. Fig. 5 describes the three visualizations on the project under construction so that the end-users of the proposed model can easily modify them. 
TABLE I

SUMMARY OF ACTIVITY SAFETY ANALYSIS

\begin{tabular}{|c|c|c|c|c|c|c|}
\hline Task & Hazard Type & Risk & Severity & Likelihood & Location & $\begin{array}{c}\text { Risk } \\
\text { Rating }\end{array}$ \\
\hline Preparation Work & $\begin{array}{l}\text { Lack of skills in } \\
\text { recognizing and } \\
\text { awareness of the } \\
\text { hazards of the } \\
\text { weather and the } \\
\text { environment it is } \\
\text { exposed to }\end{array}$ & $\begin{array}{l}\text { tripping and falling, being } \\
\text { trampled, falling objects }\end{array}$ & 5 & 3 & $\begin{array}{l}\text { B1, B2, B3, } \\
1^{\text {st }} F L, 2^{\text {nd }} \\
\text { FL, } 3^{\text {rd }} F L\end{array}$ & 15 \\
\hline Inclinometer Work & $\begin{array}{l}\text { Ground } \\
\text { movement }\end{array}$ & Landslide, collapse of structure & 5 & 3 & $\begin{array}{l}\mathrm{B} 1, \mathrm{~B} 2, \mathrm{~B} 3, \\
1^{\text {st }} \mathrm{FL}, 2^{\text {nd }} \\
\text { FL, } 3^{\text {rd }} \mathrm{FL}\end{array}$ & 15 \\
\hline $\begin{array}{l}\text { Kingpost Top- } \\
\text { Down construction }\end{array}$ & $\begin{array}{l}\text { Installation of } \\
\text { tools and work } \\
\text { material kingpost }\end{array}$ & $\begin{array}{l}\text { falling loads from cranes, falling } \\
\text { objects, fatigue }\end{array}$ & 5 & 4 & $\mathrm{~B} 1, \mathrm{~B} 2, \mathrm{~B} 3$ & 20 \\
\hline $\begin{array}{l}\text { Kingpost } \quad \text { Top- } \\
\text { Down construction }\end{array}$ & Kingpost work & $\begin{array}{l}\text { The dangers of illness due to } \\
\text { exposure to very extreme } \\
\text { temperatures include } \\
\text { dehydration, exposure to } \\
\text { excessive light and temperature, } \\
\text { accidents that result in an impact } \\
\text { on the head, and all parts of the } \\
\text { body including cuts, wounds } \\
\text { with translucent body parts, } \\
\text { injured eyes, wounds originating } \\
\text { from impact, as well as the } \\
\text { impact of safety hazards that } \\
\text { increase significantly over a long } \\
\text { period of time such as noise and } \\
\text { dust exposure. }\end{array}$ & 5 & 4 & B1, B2, B3 & 20 \\
\hline $\begin{array}{l}\text { Trenching and } \\
\text { excavation work }\end{array}$ & $\begin{array}{l}\text { Basement } \\
\text { excavation and } \\
\text { unsafe } \\
\text { excavation soil } \\
\text { disposal } \\
\end{array}$ & $\begin{array}{l}\text { collapse cranes, landslides, gas } \\
\text { inhalation, falling objects, crash } \\
\text { by excavators, property damage, } \\
\text { the downfall of dump trucks }\end{array}$ & 5 & 3 & $\mathrm{~B} 1, \mathrm{~B} 2, \mathrm{~B} 3$ & 15 \\
\hline Shear wall work & $\begin{array}{l}\text { Shear wall } \\
\text { erection } \\
\text { inappropriate } \\
\text { method }\end{array}$ & $\begin{array}{l}\text { Shear wall falls, falls from } \\
\text { height, tower crane sling breaks } \\
\text { up, noise }\end{array}$ & 5 & 3 & B1, B2, B3 & 15 \\
\hline Shear wall work & $\begin{array}{l}\text { Shear wall } \\
\text { casting without } \\
\text { working method } \\
\end{array}$ & $\begin{array}{l}\text { Crash bucket concrete, falling } \\
\text { into the shear wall area, falling } \\
\text { concrete pile from top floor }\end{array}$ & 5 & 5 & $\mathrm{~B} 1, \mathrm{~B} 2, \mathrm{~B} 3$ & 25 \\
\hline Beam and Slab & $\begin{array}{l}\text { Using of damage } \\
\text { or unproperly } \\
\text { scaffold }\end{array}$ & $\begin{array}{l}\text { objects falling from a height, the } \\
\text { collapse of the scaffolding, } \\
\text { falling due to their own } \\
\text { negligence such as falling and } \\
\text { being touched by falling objects }\end{array}$ & 5 & 3 & B1, B2, B3 & 15 \\
\hline Beam and Slab & $\begin{array}{l}\text { Lack of or wrong } \\
\text { design of rebar } \\
\text { case }\end{array}$ & $\begin{array}{l}\text { Scratched or cut but sharp edges, } \\
\text { Rebar case falls or rolls over, } \\
\text { Hazard of pinched by materials, } \\
\text { Rebar Case collapse }\end{array}$ & 5 & 3 & B1, B2, B3 & 15 \\
\hline Beam and Slab & $\begin{array}{lr}\text { casting } & \text { floors } \\
\text { without } & \text { work } \\
\text { shifts } & \\
\end{array}$ & $\begin{array}{l}\text { Dropped load due to failure of } \\
\text { lifting equipment components or } \\
\text { failure of lifting gear / } \\
\text { accessories, Noise level } \\
\text { exposure }\end{array}$ & 5 & 3 & $\begin{array}{l}\text { B1, B2, B3, } \\
\text { 1st FL, 2nd } \\
\text { FL, 3rd FL }\end{array}$ & 15 \\
\hline Beam and Slab & $\begin{array}{l}\text { use tools for } \\
\text { access and } \\
\text { platforms that are } \\
\text { not standard }\end{array}$ & $\begin{array}{l}\text { There is financial loss and } \\
\text { damage due to falling objects. } \\
\text { Entanglement of body parts by } \\
\text { material, injury from falls and } \\
\text { collisions of objects falling from } \\
\text { a height. }\end{array}$ & 5 & 3 & B1, B2, B3 & 15 \\
\hline
\end{tabular}



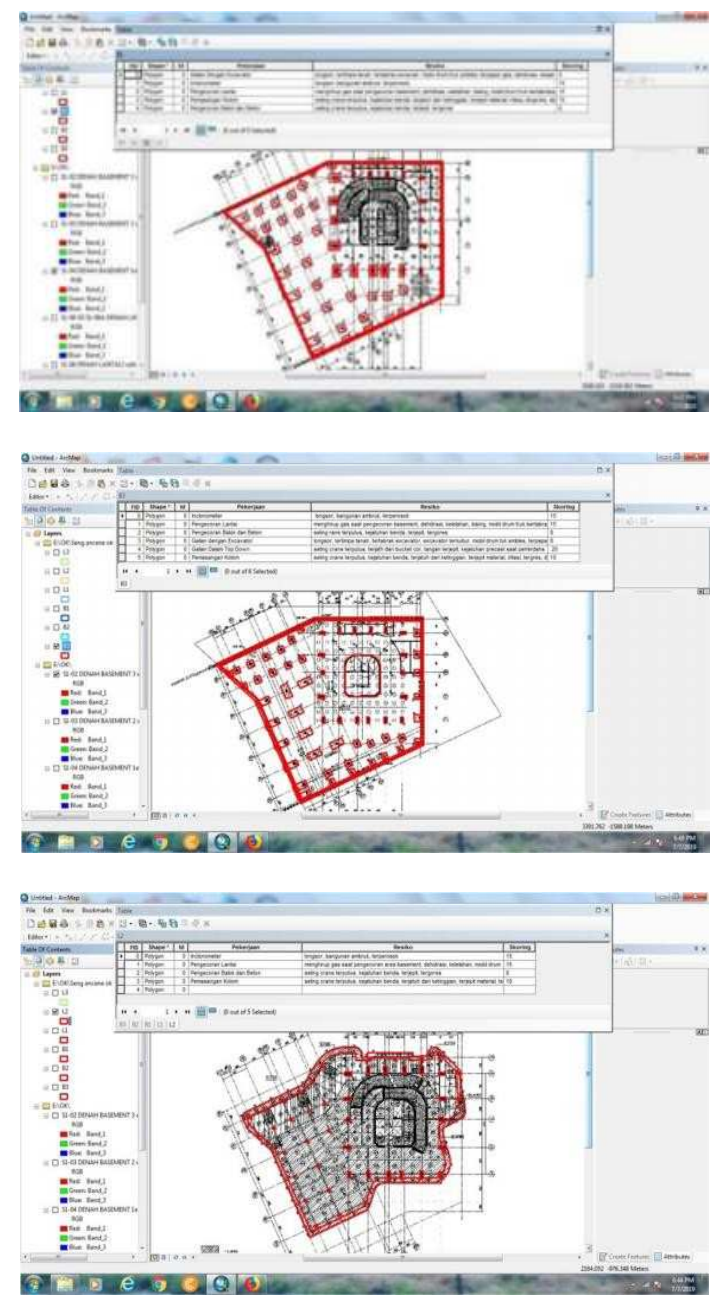
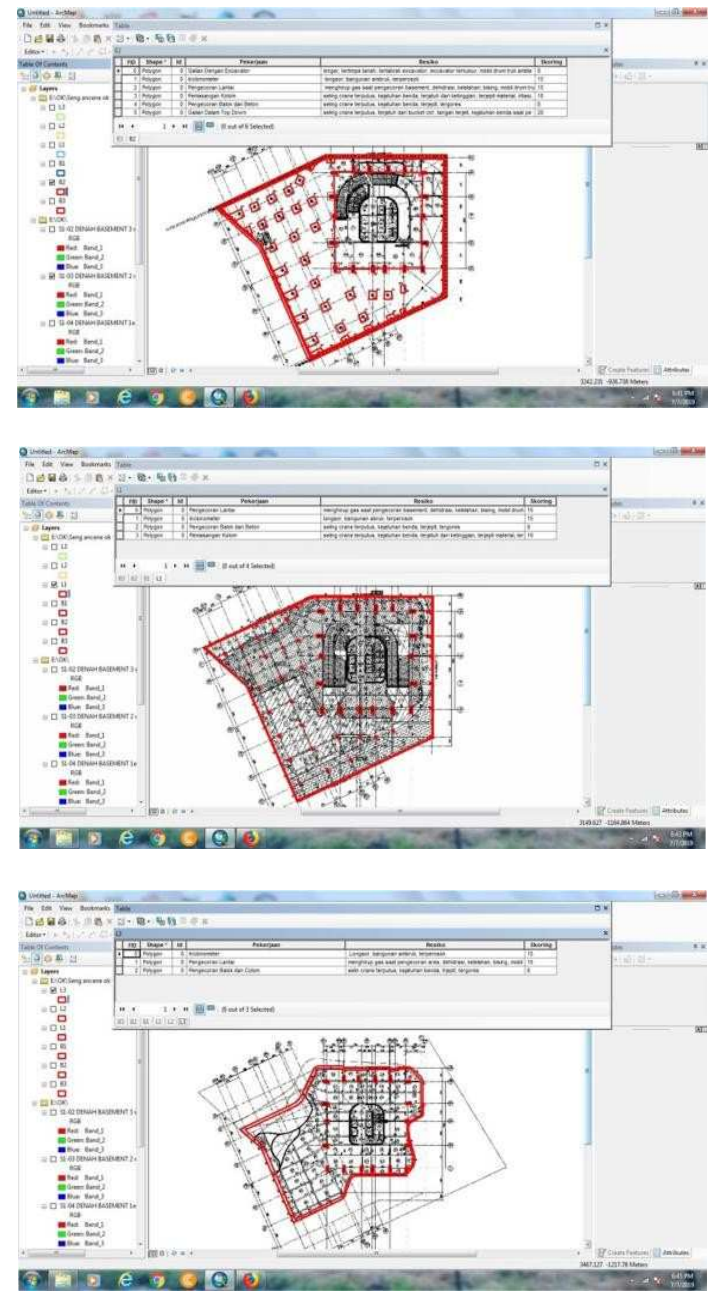

Fig. 4 Model of high rise building along with its surrounding developed in ArcGIS and specific analysis in the zone of basement 3, basement 2, basement 1, 1st floor, 2nd floor, and 3rd floor.

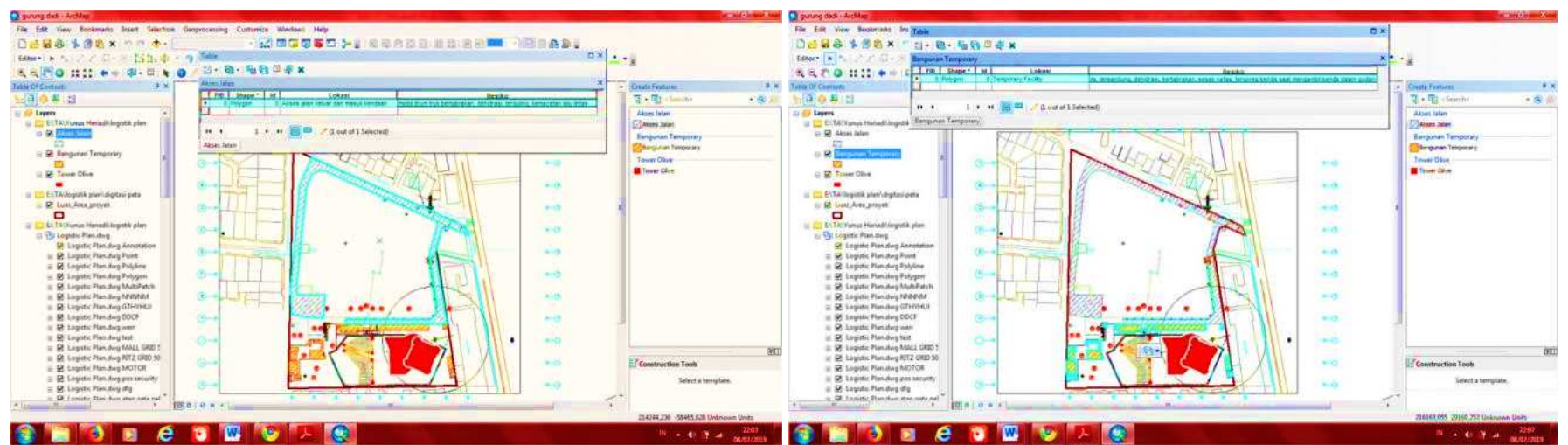

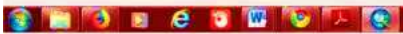

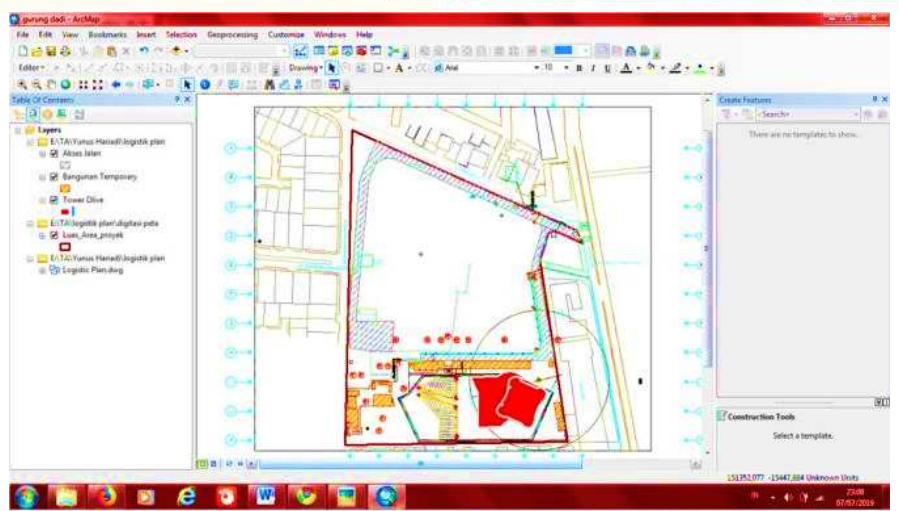

Fig. 5. Work zone risk was classified 
The results of the analysis summarize some of the activities carried out less consistently. However, the systematic steps specifically help stakeholders in developing a safety plan. The historical database provides a safety risk analysis framework that can explain the occurrence of hazardous work zones and activities. The development of a safety plan is limited in the short term. A GIS analysis can be carried out at the beginning of construction to prepare and predict safety risks in the long-term. The availability of color indicator visualization on the site's topography provides a warning system for construction players to safely use all available areas. Guidelines for effective and safe vehicle access points, implementation of handles, guardrails, warning boards and falling protection measures to protect workers on site. The animation findings also provide steps to start some activities by repeating scheduling to ensure a safe work area during construction.

In the construction planning, geographically, the project site conditions are essential. The use of GIS on-site can maintain spatial and non-spatial data from construction sites by importing CAD-based systems. This research is a form of development of integrated thinking framework in 3D modelling from project planning to construction to support workplace safety. Construction with collaborative and interactive GIS-based topology. GIS development helps in identifying hazardous zones at project sites.

In safety, planning identified the most dangerous jobs are only a few jobs. The most hazardous rating occurs on concrete sliding walls. This work has a possible hazard, namely the falling of the concrete bouquet during the lifting process from the tower crane, falling objects from a height into the shear wall excavation on the raft foundation, and falling concrete pile on the top floor, wall collapse due to unstable soil causing Ranking of the most dangerous zone for shear wall work. In the top-down kingpost job is the most dangerous job with the existing job positions on each floor. This job is ranked the highest because it is the most at risk of experiencing a collision from falling objects from a height.

Workers' exposure to excessive light and noise from heavy equipment as well as dust exposure is a challenge in the job. Beam and column construction are ranked next as a job with a dangerous work zone due to a series of activities in it. Activities include susceptibility to falling objects from the upper floor, inadequate and damaged scaffolding, installation of rebar on edges where there are no guardrails, rebar cuts that do not comply with the provisions of the bending bar causing torn wounds, falling concrete bouquets from the tower crane and exposure to noise that triggers the occurrence, fatigue, and stress. The excavation work is the next job with a hazard with a source of danger due to the danger of falling material from above, inadequate excavators, exposure to toxic gases, landslides, and falling objects from above.

The analysis of the safety risks of activities carried out in a systematic step by step manner assists SHE managers in developing a safety plan. This step is done because the framework and guidelines are not legally owned consistently. The importance of proactive analysis is an obstacle in the field by SHE managers. Lack of anticipatory actions, limited tools in predicting the location of activities and time based on daily and weekly periods as well as a lack of experience and knowledge of risk analysis are also reasons.

The suggestions in this research analysis can provide an overview of why certain activities are a source of danger based on historical data. The SHE managers explained the reason for construction work in dangerous zone conditions because they were still limited by ineffective instructional efforts based on experience and knowledge. The development of an approach from the actual conditions of the problems in the field provides an overview of hazards and injuries in improving real-time occupational safety and health management.

Prediction in the construction period gives the SHE manager an advantage over the long term so that adequate and sustained preventive measures and safety inspections can be provided at the start of a construction project. The visualization of the safety simulation developed in this study can provide improved communication between stakeholders in the construction sector so that the project can fulfil the progress as planned.

Dynamically, the work location zone can be changed and updated so that manually increasing the activities' safety score can be a source of error. A process of scaling up the allocation of all activities and a zoning plan is needed as construction is tough to predict. Lack of knowledge in running software programs is a challenge for SHE managers to carry out training and skills in integrating construction data and safety plans so that the recommended model can be applied systematically optimally.

\section{CONCLUSION}

The GIS model is used in this study as a tool with a tracking system and an animated display to facilitate ease in understanding and predicting places, activities that have the potential for fatalities. The use of methods that can only accommodate information in the form of regulations, company policies on safety, and work drawings in 2D. Of the planned activities, 35 activities were identified as the most critical hazard category in the inspected apartment building in basements 1, 2, 3, and floor 1,2, and 3 that has been indicated 20 risk rating kingpost top-down construction and 25 risks rating included shear wall concrete activity. Data regarding workers exposed and when the hazard will occur, and the location of hazardous zones have not been analyzing in detail. This study presents the integration of temporal safety information and spatial location data in the percentage of construction safety planning in 3D.

The integration of the analysis data provides positive stimulation for awareness of work safety at the construction site. Also, periodic, and proactive updates provide planning for safety locations at the macro level as recommendations for the establishment of a framework for optimizing safety management in the workplace. From the location survey and activity data in the case study, the work zone's safety is analyzed to focus on the concentration of safety risks at the work location based on the planned site zoning. In making it easier for stakeholders to construct, it is depicted with visualization in color indicators which are classified into three categories, namely green for jobs with a relatively low level of risk, the medium risk is visualized in blue, and for jobs that have the most dangerous and critical zones 
described in red. Validation of approaches and large-scale testing with different types of projects is recommended for future research by using more specific safety risk data which is very helpful in improving safety and risk ranking, thus minimizing the occurrence of fatalities.

\section{REFERENCES}

[1] M. Behm, "Linking construction fatalities to the design for construction safety concept," Saf. Sci., vol. 43, no. 8, pp. 589-611, 2005.

[2] M. Shin, H. S. Lee, M. Park, M. Moon, and S. Han, "A system dynamics approach for modeling construction workers' safety attitudes and behaviors," Accid. Anal. Prev., vol. 68, pp. 95-105, 2014.

[3] D. Sarasanty, T. J. Wahyu Adi, and I. P. A. Wiguna, "Probabilistic Model for Predicting Construction Worker Accident Based on Bayesian Belief Networks," IPTEK J. Proc. Ser., vol. 3, no. 6, 2017.

[4] V. K. Bansal, "Integrated CAD and GIS-Based Framework to Support Construction Planning: Case Study,” J. Archit. Eng., vol. 23, no. 3, pp. 1-13, 2017.

[5] X. Ning, J. Qi, and C. Wu, "A quantitative safety risk assessment model for construction site layout planning," Saf. Sci., vol. 104, no. October 2017, pp. 246-259, 2018.

[6] J. W. Seo and H. H. Choi, "Risk-based safety impact assessment methodology for underground construction projects in Korea," $J$. Constr. Eng. Manag., vol. 134, no. 1, pp. 72-81, 2008.

[7] R. M. Choudhry, D. Fang, and S. M. Ahmed, "Safety management in construction: Best practices in Hong Kong," J. Prof. Issues Eng. Educ. Pract., vol. 134, no. 1, pp. 20-32, 2008.

[8] M. Esmaeili, B; Hallowell, "Diffusion of Safety Innovations in the Construction Industry," J. Constr. Eng. Manag., vol. 138, no. January, pp. 51-60, 2013.

[9] E. Hegazy, Tarek; Elbeltagi, "Evosite: Evolution-Based Model For Site Layout Planning," J. Comput. Civ. Eng., vol. 13, pp. 198-206, 1999.

[10] X. Su, A. R. Andoh, H. Cai, J. Pan, A. Kandil, and H. M. Said, "GISbased dynamic construction site material layout evaluation for building renovation projects," Autom. Constr., vol. 27, pp. 40-49, 2012.

[11] U. Isikdag, J. Underwood, and G. Aouad, "An investigation into the applicability of building information models in geospatial environment in support of site selection and fire response management processes," Adv. Eng. Informatics, vol. 22, no. 4, pp. 504-519, 2008.

[12] K. El-Rayes and A. Khalafallah, "Trade-off between safety and cost in planning construction site layouts," J. Constr. Eng. Manag., vol. 131, no. 11, pp. 1186-1195, 2005.

[13] C. Anumba and G. Bishop, "Importance of safety considerations in site layout and organization," Can. J. Civ. Eng., vol. 24, no. 2, pp. 229-236, 1997.

[14] A. J. Khattak and H. Shamayleh, "Highway safety assessment through geographic information system-based data visualization," $J$. Comput. Civ. Eng., vol. 19, no. 4, pp. 407-411, 2005.

[15] S. J. Guo, "Identification and resolution of work space conflicts in building construction," J. Constr. Eng. Manag., vol. 128, no. 4, pp. 287-295, 2002.

[16] D. Riely and V. Sanvido, "Patterns Of Construction-Space Use In Multistory Buildings By David R . Riley · and Victor E . Sanvido , 2 Associate Members , ASCE," J. Constr. Eng. Manag., no. December, pp. 464-473, 1995.

[17] S. Razavialavi and S. AbouRizk, "Site Layout and Construction Plan Optimization Using an Integrated Genetic Algorithm Simulation
Framework," J. Comput. Civ. Eng., vol. 31, no. 4, pp. 1-10, 2017.

[18] M. Xu, Z. Mei, S. Luo, and Y. Tan, "Optimization algorithms for construction site layout planning: a systematic literature review," Eng. Constr. Archit. Manag., 2020.

[19] F. Zhou, S. M. AbouRizk, and H. AL-Battaineh, "Optimisation of construction site layout using a hybrid simulation-based system," Simul. Model. Pract. Theory, vol. 17, no. 2, pp. 348-363, 2009.

[20] P. L. Le, T. M. Dao, and A. Chaabane, "BIM-based framework for temporary facility layout planning in construction site: A hybrid approach," Constr. Innov., vol. 19, no. 3, pp. 424-464, 2019.

[21] X. Ning, J. Qi, C. Wu, and W. Wang, "Reducing noise pollution by planning construction site layout via a multi-objective optimization model," J. Clean. Prod., vol. 222, pp. 218-230, 2019.

[22] X. Song, J. Xu, C. Shen, and F. Peña-Mora, "Conflict resolutionmotivated strategy towards integrated construction site layout and material logistics planning: A bi-stakeholder perspective," Autom. Constr., vol. 87, no. December 2017, pp. 138-157, 2018.

[23] T. H. Nguyen, A. A. Oloufa, and K. Nassar, "Algorithms for automated deduction of topological information," Autom. Constr., vol. 14, no. 1, pp. 59-70, 2005.

[24] W. Jiang, Y. Zhou, L. Ding, C. Zhou, and X. Ning, "UAV-based 3D reconstruction for hoist site mapping and layout planning in petrochemical construction," Autom. Constr., vol. 113, no. February, 2020.

[25] C. Wu, N. Li, and D. Fang, "Leadership improvement and its impact on workplace safety in construction projects: A conceptual model and action research," Int. J. Proj. Manag., vol. 35, no. 8, pp. 1495-1511, 2017.

[26] P. C. Lee, Y. Wang, T. P. Lo, and D. Long, "An integrated system framework of building information modelling and geographical information system for utility tunnel maintenance management," Tunn. Undergr. Sp. Technol., vol. 79, no. April, pp. 263-273, 2018.

[27] M. Y. Cheng and J. T. O'Connor, "Arcsite: Enhanced GIS for construction site layout," J. Constr. Eng. Manag., vol. 122, no. 4, pp. 329-336, 1996.

[28] M. Y. Cheng and J. T. O'Connor, "Site layout of construction temporary facilities using an enhanced-geographic information system (GIS)," Autom. Constr., vol. 3, no. 1, pp. 11-19, 1994.

[29] X. Su and H. Cai, "Enabling Construction 4D Topological Analysis for Effective Construction Planning," J. Comput. Civ. Eng., vol. 30, no. 1, pp. 1-10, 2016.

[30] S. Choe and F. Leite, "Construction safety planning: Site-specific temporal and spatial information integration," Autom. Constr., vol. 84, no. August 2016, pp. 335-344, 2017.

[31] W. Yi, H. L. Chi, and S. Wang, "Mathematical programming models for construction site layout problems," Autom. Constr., vol. 85, no. May 2017, pp. 241-248, 2018.

[32] K. Schwabe, J. Teizer, and M. König, "Applying rule-based modelchecking to construction site layout planning tasks," Autom. Constr., vol. 97, no. October 2018, pp. 205-219, 2019.

[33] X. Liu, X. Wang, G. Wright, J. C. P. Cheng, X. Li, and R. Liu, "A state-of-the-art review on the integration of Building Information Modeling (BIM) and Geographic Information System (GIS)," ISPRS Int. J. Geo-Information, vol. 6, no. 2, pp. 1-21, 2017.

[34] C. W. Liu, T. H. Wu, M. H. Tsai, and S. C. Kang, "Image-based semantic construction reconstruction," Autom. Constr., vol. 90, no. February, pp. 67-78, 2018.

[35] F. Sandrone and V. Labiouse, "A GIS based approach for analysing geological and operation conditions influence on road tunnels degradation," Tunn. Undergr. Sp. Technol., vol. 66, no. November 2016, pp. 174-185, 2017.

[36] S. Yamamura, L. Fan, and Y. Suzuki, "Assessment of Urban Energy Performance through Integration of BIM and GIS for Smart City Planning," Procedia Eng., vol. 180, pp. 1462-1472, 2017. 